\title{
SCIENTIFIC REPORTS

\section{OPEN Ultrafast microwave synthesis of rambutan-like CMK-3/carbon nanotubes nanocomposites for high-performance supercapacitor electrode materials}

\begin{abstract}
KeYan, Xin Sun, ShuYing, Wen Cheng, Yu Deng, Zhong Ma, Yu Zhao, Xinran Wang, Lijia Pan ${ }^{*}$ \& YiShi* $^{*}$

Ordered mesoporous carbon materials show great potential for electric double-layer supercapacitors because of their high specific surface area, designable pore structure, and tunable morphology. However, low graphitic crystallinity nature and poor contact between particles lead to their high inherent resistance, which limits the supercapacitance performance. Herein, we report on a hierarchically rambutan-morphological design of carbon composites with ordered mesoporous carbon as the core and carbon nanotubes as the shell, which significantly improve the electric contact between mesoporous carbon particles and promote the electrochemical performance. By an ultrafast microwave process in a household microwave heater under ambient condition, carbon nanotubes grow out from the pores of ordered mesoporous carbon and are dispersed on its surface like the whiskers of rambutan. As-synthesized ordered mesoporous carbon CMK-3/carbon nanotubes nanocomposites show significantly enhanced specific capacitance $\left(315.6 \mathrm{~F} \cdot \mathrm{g}^{-1}\right.$ at $1 \mathrm{~A} \cdot \mathrm{g}^{-1}$, as compared with $172.1 \mathrm{~F} \cdot \mathrm{g}^{-1}$ of CMK-3), high rate capability $\left(214.6 \mathrm{~F} \cdot \mathrm{g}^{-1}\right.$ at $\left.50 \mathrm{~A} \cdot \mathrm{g}^{-1}\right)$, and cycling durability $(10,000$ cycles, $99.32 \%)$. The structural design and microwave synthesis enable a facile preparation of the hybrid ordered mesoporous carbon CMK-3/carbon nanotubes nanocomposites, and show potential for easy and lowcost production of high performance electric double-layer supercapacitors materials.
\end{abstract}

In recent years, conflicts between energy-consuming and global ecology have urged researchers to develop new energy conversion and storage technologies with efficient, environmental-friendly, and sustainable features ${ }^{1,2}$. Supercapacitors (also known as Electrochemical capacitors) nowadays increasingly attract the attention of researchers and have been considered as promising devices for future energy storage applications, with the advantages of high power rating compared with batteries, large energy density compared with dielectric capacitors, and excellent charge-discharge stability ${ }^{3-10}$. Based on the energy storage mechanism, it can be divided into pseudocapacitors (typically produced with electro-active materials, such as transition metal oxides and conducting polymers), and electric double-layer supercapacitors (EDLCs, with non-redox materials, such as active carbon, porous carbon, etc.). For EDLCs, energy storage is achieved by electrostatic interaction of electron charge in the electrode and adsorbed ions in a Helmholtz double layer at the interface between electrode/electrolyte. Owing to the non-Faradaic process of charging/discharging, carbon-based EDLCs endow high reversibility and stability in aqueous electrolyte ${ }^{11}$. However, due to poor electric contact between active material particles and inefficient ion diffusion in the pore structures, relatively low energy density and poor rate performance hinder EDLCs practical applications and further development ${ }^{12,13}$.

To deal with these challenges, various materials were developed to improve the EDLCs performance, and carbon-based nanostructures were among the best of them ${ }^{14-24}$. Ordered mesoporous carbon CMK-3 was one of the promising materials because of the high surface-area-to-mass ratio mesopores (pore diameters between 2

Jiangsu Provincial Key Laboratory of Photonic and Electronic Materials, Collaborative Innovation Center of Advanced Microstructures, School of Electronic Science and Engineering, Nanjing University, Nanjing, 210093, China. *email: ljpan@nju.edu.cn; yshi@nju.edu.cn 
and $50 \mathrm{~nm}$ ), aligned channel for promoted ion diffusion, and modifiable surface morphology ${ }^{25-28}$. However, the low graphitic crystallinity nature of CMK-3 and ineffective electric contact between CMK-3 particles generally resulted in high inherent resistance of the electrodes which seriously restricted the charge and discharge efficiency, and thus limited the electrochemical performance of CMK-3 (usually exhibiting a specific capacitance of $\left.\sim 150 \mathrm{~F} \cdot \mathrm{g}^{-1}\right)^{29,30}$. On the other hand, carbon nanotubes (CNTs) was considered as another potential EDLCs electrode material because of the unique electrical, mechanical, and chemical properties ${ }^{31,32}$. CNTs have superior electrical conductivity than amorphous carbon materials, which endow them with high electron transport efficiency and good rate performance; in addition, mechanical robustness of CNTs can reduce the cycle degradation of capacity during the charging and discharging process. Nevertheless, the CNTs electrodes generally have a specific capacitance of fewer than $100 \mathrm{~F} \cdot \mathrm{g}^{-1}$ because of the few effective pore structures for ion diffusion.

Designing and fabricating composites of CMK-3 and CNTs to effectively couple their advantages can be a good solution to the aforementioned challenges. There were some previous works reported on the physically mixing of CNTs and CMK-3 particles, in which CNTs acted as the conductive binder to enhance the electron transport. Some other works tried to use the conventional Chemical vapor deposition (CVD) process to synthesize CNTs on CMK-3 particles' surface ${ }^{33-36}$. However, these approaches also suffered from the weakened binder connection and bad electric contact between CMK-3 and CNTs. Moreover, the CVD process was relatively hard to control, time-consuming, and high-cost. Nowadays, microwave techniques have been applied in synthesis and modification of nanomaterials for their fast, energy-saving, and controllable specialties ${ }^{37-41}$.

Herein, we proposed an ultrafast microwave synthesized rambutan-like CMK-3/carbon nanotubes nanocomposites with improved electric contact between mesoporous carbon particles and significantly enhanced supercapacitance performance. CMK-3 acted as the microwave-absorbing conductive layer, and ferrocene was filled in the nanochannels of CMK-3 to form nanoparticles. The local heating induced by microwave irradiation, within only 10 30 seconds, decomposed ferrocene into Fe nanoparticles and catalyzed the growth of CNTs out of the CMK-3 nanochannels. As-synthesized CMK-3/CNTs nanocomposites showed the morphology like rambutans with CNTs whiskers, which significantly enhanced the electric contact by $3 \mathrm{D}$ interconnecting routes between CMK-3 particles. Superior EDLCs performances were observed, such as enhanced specific capacitance $\left(315.6 \mathrm{~F} \cdot \mathrm{g}^{-1}\right.$ at a current density of $\left.1 \mathrm{~A} \cdot \mathrm{g}^{-1}\right)$, high rate capability $\left(214.6 \mathrm{~F} \cdot \mathrm{g}^{-1}\right.$ at $\left.50 \mathrm{~A} \cdot \mathrm{g}^{-1}\right)$ and excellent cycling stability (99.32\% after 10,000 cycles). The results show that the ultrafast microwave synthesized CMK-3/CNTs nanocomposites have great potential for high-performance supercapacitor applications. The microwave synthesis and convenient precursors could provide with an ultrafast, easy procedure, and low-cost approach for massive commercial production of the supercapacitor electrode materials.

\section{Results and Discussion}

Formation mechanism of CMK-3/CNTs nanocomposites. The structure of CMK-3/CNTs is schematically illuminated in Figure 1a. The synthesis process can be divided into two steps. In the first step, under microwave heating, ferrocene precursors trapped in the CMK-3 were decomposed into Fe catalysts with sizes precisely defined by the nanochannels of CMK-3 (Figure 1b-d). The mixture surface temperature got up to $390^{\circ} \mathrm{C}$ in seconds as measured by thermal imager (Fig. S1) and the instantaneous local temperature was estimated over $1000^{\circ} \mathrm{C}$ due to the heat release of sparks and arcs according to previously reported ${ }^{42}$. The second step (Figure $1 \mathrm{~d}, \mathrm{e}$ ) is the tip-growth of CNTs catalyzed by nano-sized Fe particles, which serve as both nucleation centers and catalysts of cyclopentadienyl (from the decomposition of ferrocene) (Fig. S2) ${ }^{43,44}$.

The CMK-3 powder acted as good heating and microwave absorption material, while it was found that the temperature of ferrocene would not raise under microwave irradiation due to its nonpolar nature ${ }^{45}$. Microwave radiation made the electric dipoles and charges of conductive material oscillate in translational motion with high frequency, and the kinetic energy produced by molecular friction turned into heat intensively and rapidly ${ }^{46,47}$. Hence, the high electrical conductivity of the CMK-3 helped the precursor absorb microwave irradiation and thus a large amount of heat was generated in a short time period. In addition, due to the low microwave penetrating depth (i.e. the ability of a material to be heated by microwave irradiation) of graphite ${ }^{42,48}$, the microwave heating was produced on the CMK-3 surface within several microns. We observed no heating, sparks or arcs generation of other mesoporous materials such as $\mathrm{SiO}_{2}$ molecular sieves under microwave radiation for the much higher penetration depth of silicon materials than graphite.

Structure and morphology of CMK-3/CNTs nanocomposites. Microwave-induced CNTs was generated on the surface of CMK-3 due to the aforementioned local-heating effects. Figure 2a shows the Transmission electron microscopy (TEM) image of a single CMK-3 particle with parallel and periodic pore structures. It has pore diameters of $3.8 \mathrm{~nm}-4.0 \mathrm{~nm}$, and carbon cylinders' diameter of $\sim 7.3 \mathrm{~nm}$. Figure $2 \mathrm{~b}$ shows the Scanning electron microscopy (SEM) image of as-synthesized CMK-3/CNTs nanocomposites, of which two particles are connected by CNTs wrapped around CMK-3. As a comparison, the pristine CMK-3 particles show bare ordered rod-like morphology without additional structure on the surface. TEM image in Figure $2 \mathrm{c}$ shows that well-crystallized CNTs pile up, forming bundles from the pore and at the end of the CMK-3. The inset of Figure $2 \mathrm{c}$ presents good graphitization of CNTs with $\sim 0.34 \mathrm{~nm}$ layer distance and Fe nanoparticles (the $\left(\begin{array}{lll}1 & 1 & 0\end{array}\right)$ plane of the Fe (JCPDS06-0696)) encapsulated in the nanotubes as catalyst (from the decomposition of ferrocene) which correlate well with the previous reports ${ }^{49,50}$.

Figure 2d shows highly dense of well-entangled CNTs (marked by red arrows) distributing on the CMK-3 particles and the bundle diameter ranges from $\sim 1 \mathrm{~nm}$ to $\sim 10 \mathrm{~nm}$ (Fig. S3). Due to the efficient in suit growth of CNTs, the adhesion and interactions between CNTs and substrates were improved to couple eligible CMK-3/ CNTs nanocomposites ${ }^{51}$.

The Raman spectra confirm the formation and coupling of CNTs. The measurements were performed at a laser excitation line of $514 \mathrm{~nm}$ and the spectra were shown in Figure 3a. As-synthesized CMK-3/CNTs nanocomposites 
a
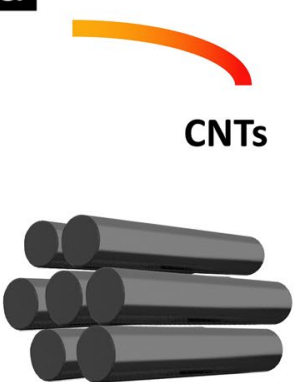

СMK-3

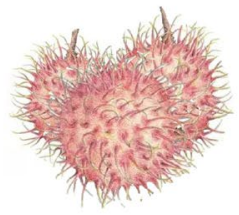

Rambutan

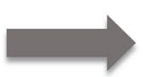

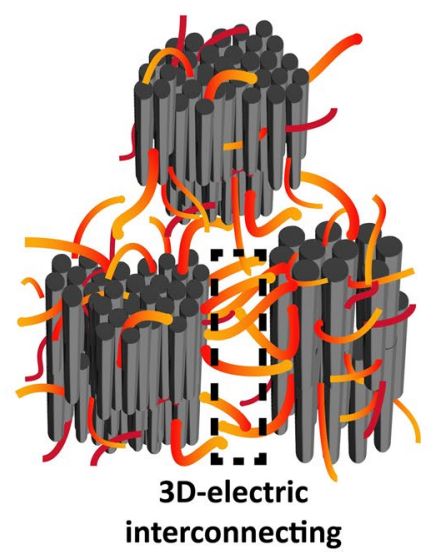
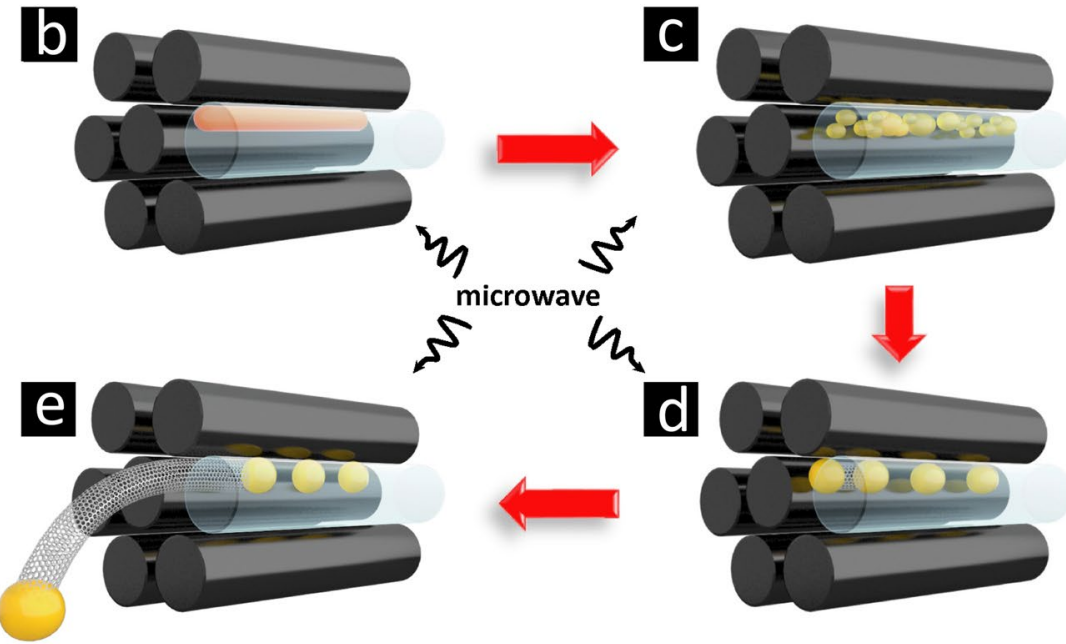
$5^{\text {microwave }}$
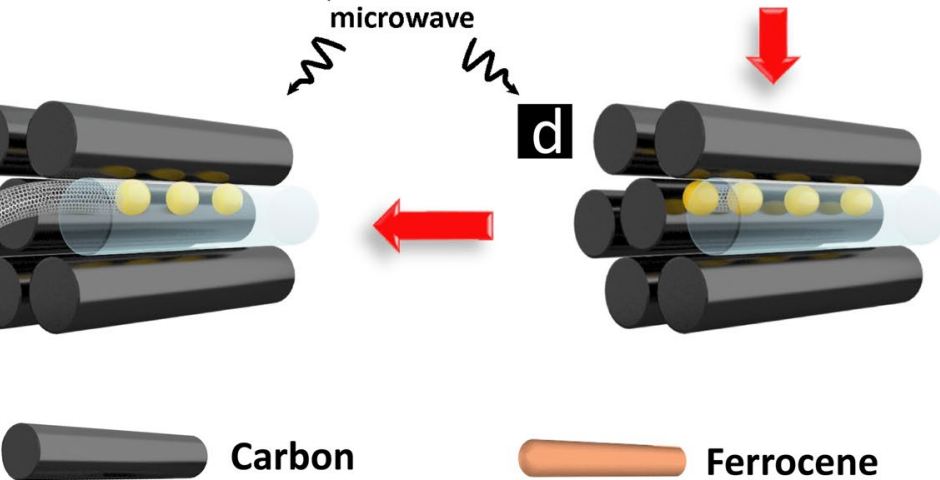

Catalyst particles

\section{CNTs}

Figure 1. (a) Schematic illustration of CNTs, CMK-3 and rambutan-like CMK-3/CNTs nanocomposites. Growth mechanism of microwave-induced CNTs: (b) Ferrocene filled in the nanochannels of CMK-3; (c) Microwave-induced ferrocene decomposition; $(\mathbf{d}, \mathbf{e})$ Iron particles catalyzed growth of CNTs.

exhibit D-band (with peaks of $1100-1400 \mathrm{~cm}^{-1}$ ) which is caused by graphite layer disorder or defects; a G-band (with peaks of $1580-1600 \mathrm{~cm}^{-1}$ ) which is related to $\mathrm{sp}^{2}$ bond of carbon atoms, denoting the existence of CNTs and good graphitic quality; and a 2D-band (with peaks double the wavelength of D-band) which comes from a second-order double resonant process. The intensity ratio of $\mathrm{D}$-band to $\mathrm{G}$-band $\left(\mathrm{I}_{\mathrm{D}} / \mathrm{I}_{\mathrm{G}}\right)$ refers to the amount, crystallized degree and purity of CNTs and the decrease of $\mathrm{I}_{\mathrm{D}} / \mathrm{I}_{\mathrm{G}}$ value proves the increase of CNTs in our sam$\mathrm{ple}^{52}$. As shown in Figure 3a, after microwave treatment for 10 seconds, as-synthesized nanocomposites showed stronger G-band and weaker D-band compared with pristine CMK-3. The $\mathrm{I}_{\mathrm{D}} / \mathrm{I}_{\mathrm{G}}$ value of pristine $\mathrm{CMK}-3$ and 10 -seconds CMK-3/CNTs nanocomposites were 1.08 and 0.60 , respectively. With the microwave treating time increasing from $10 \mathrm{~s}$ to $30 \mathrm{~s}, \mathrm{G}$-band peaks were further promoted while the $\mathrm{I}_{\mathrm{D}} / \mathrm{I}_{\mathrm{G}}$ value was further reduced to 0.50 . However, when treated for more than $30 \mathrm{~s}$ microwave radiation, no obvious enhancement of $\mathrm{I}_{\mathrm{D}} / \mathrm{I}_{\mathrm{G}}$ value was observed because synthesis finished within just $30 \mathrm{~s}$ and more reaction time brought no extra CNTs formation. Besides, the $\mathrm{I}_{\mathrm{D}} / \mathrm{I}_{\mathrm{G}}$ values of CMK-3/CNTs nanocomposites synthesized with different concentration of ferrocene are shown in Table S1 with Atomic absorption spectrometry (AAS), showing that the most CNTs-productive approach of the synthesis process is the use of $80 \mathrm{wt}$.\% ferrocene-saturated benzene solution.

The X-ray diffraction (XRD) patterns of the CMK-3/CNTs nanocomposites are shown in Figure 3b. The XRD patterns show the crystallographic structure of the sample. The diffraction peak of $26.4^{\circ}$ is assigned to the (002) reflection of graphite. The XRD patterns of the CMK-3/CNTs nanocomposites before acid treatment are shown in Fig. S4A. The Small-angle X-ray scattering (SAXS) patterns of CMK-3 and CMK-3/CNTs nanocomposites are shown in Fig. S4B which revealed their well-ordered mesoporous structures with unit cell parameters calculated 

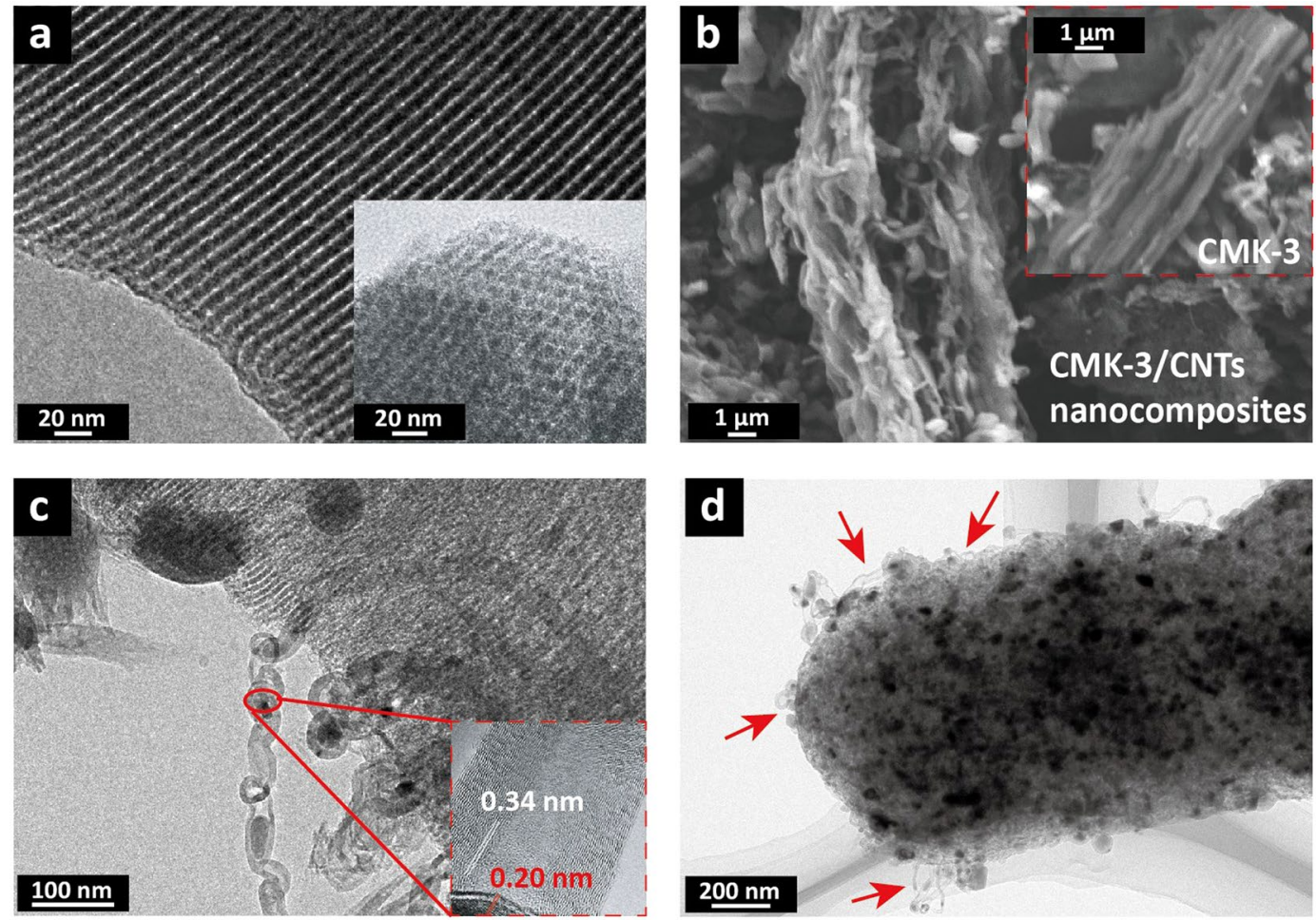

Figure 2. (a) TEM image of pristine CMK-3 nanochannels; Inset, hexagonal ordered mesostructured view of CMK-3; (b) SEM image of as-synthesized CMK-3/CNTs nanocomposites, of which two particles are connected by CNTs wrapped around CMK-3; Inset, pristine CMK-3 particles; (c) TEM images of CNTs in bundles synthesized by the microwave process; Inset, electron diffraction pattern of CNTs and catalyst particles; (d) TEM images of CNTs protruding from the mesoporous nanochannels of CMK-3.

to be $\sim 11.3 \mathrm{~nm}$. Energy dispersive X-Ray spectroscopy (EDX) and X-ray photoelectron spectroscopy (XPS) were used to further characterize as-synthesized CMK-3/CNTs nanocomposites. EDX pattern (Fig. S5) is sensitive to trace amounts of elemental content in the CMK-3/CNTs nanocomposites and thus identify the purity. The elemental contents of CMK-3/CNTs nanocomposites are $\mathrm{C}, \mathrm{O}$, and $\mathrm{Fe}$ ( $\mathrm{Cu}$ peaks caused by TEM copper net) corresponding to previous measurements that no other elements are introduced within the synthesis process. XPS is conducted to analyze the chemical bond types and the functional groups on the CMK-3/CNTs nanocomposites. The full-range XPS spectra of CMK-3 and CMK-3/CNTs nanocomposites are presented in Figure 3c. It shows that $\mathrm{C} 1 \mathrm{~s}$ and $\mathrm{O} 1 \mathrm{~s}$ peak are enhanced by the formation of $\mathrm{CNTs}^{53}$. As shown in Figure $3 \mathrm{~d}$, the $\mathrm{C} 1 \mathrm{~s}$ peaks are resolved into three peaks (at $284.6 \mathrm{eV}, 286 \mathrm{eV}$, and $288.5 \mathrm{eV}$, representing $\mathrm{C}-\mathrm{C} / \mathrm{C}=\mathrm{C}, \mathrm{C}-\mathrm{OH}$ and $\mathrm{COOH}$, respectively $)^{54}$. CMK-3/CNTs nanocomposites (top) exhibit enhanced $\mathrm{C}-\mathrm{OH}$ and $\mathrm{COOH}$ peaks, compared with pristine CMK-3 (bottom) which is ascribed to the oxidization and heating environment within the microwave synthesis process. Also, hydrophilic property of the CNTs surface could be promoted through the microwave oxidization and heating treatments for the functional groups' introduction. In Figure $3 \mathrm{e}$, the distributions of pore sizes are given, derived from desorption data using the Barrett-Joyner-Halenda (BJH) model. It shows most of the pore diameters fall into $2.0-10.0 \mathrm{~nm}$ and the diameter peaks of CMK-3 and CMK-3/CNTs nanocomposites are calculated to be around $3.9 \mathrm{~nm}$ and $3.6 \mathrm{~nm}$. The average pore diameters are narrowed after the presence of CNTs. The N2 adsorption-desorption isotherm curves in Figure $3 \mathrm{f}$ indicate a sharp uprising below $P / P_{0}=0.02$ and a hysteresis loop above $P / P_{0}=0.6$, corresponding to type III curve and type $\mathrm{H}-3$ loop in IUPAC classification which are characteristics of uniform mesoporous particles ${ }^{55}$. A large specific surface area $\left(1108.74 \mathrm{~cm}^{2} \cdot \mathrm{g}^{-1}\right)$ and pore volume $\left(1.58 \mathrm{~cm}^{3} \cdot \mathrm{g}^{-1}\right)$ were obtained from the CMK-3 which provided active sites and channels for the adsorption and diffusion of electrolyte ions. For the CMK-3/CNTs nanocomposites, the specific surface area and pore volume were changed to $801 \mathrm{~m}^{2} \cdot \mathrm{g}^{-1}$ and $1.16 \mathrm{~cm}^{2} \cdot \mathrm{g}^{-1}$, respectively. The decrease of both specific surface area and pore volume and the changes of pore size distribution are probably owing to the microwave synthesized CNTs located between the pore of CMK-3. However, this slight decrease of the specific surface area and pore volume have little effect on the capacitive properties of the CMK-3/CNTs nanocomposites as we can see in electrochemical measurements. The results further confirm that the capacitance has more than a simple linear relationship with the surface area ${ }^{56}$. So this approach to promote the contact and electrical conductivity between CMK-3 particles is effective towards enhanced electrochemical properties, instead of simply modifying the pore structures.

Differential Scanning Calorimetry (DSC) measurement was carried out with a temperature range of $20^{\circ} \mathrm{C}$ to $1000^{\circ} \mathrm{C}$. The DSC curve of precursor shows 1 main peak at about $440^{\circ} \mathrm{C}$ and 2 shoulder peaks at $360^{\circ} \mathrm{C}$ and $530^{\circ} \mathrm{C}$ (Fig. S6A). It is supposed that the main peak is the decomposition of amorphous carbon and the shoulder peak at $360^{\circ} \mathrm{C}$ denotes the ferrocene decomposition temperature ${ }^{57}$. Thermogravimetric analysis (Fig. S6B) 
a

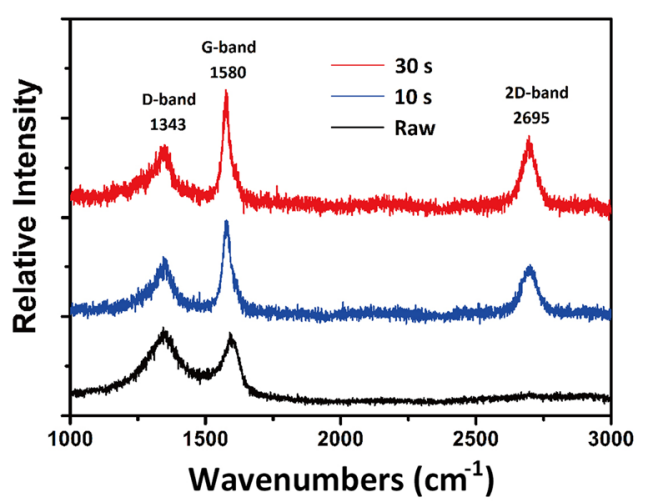

C

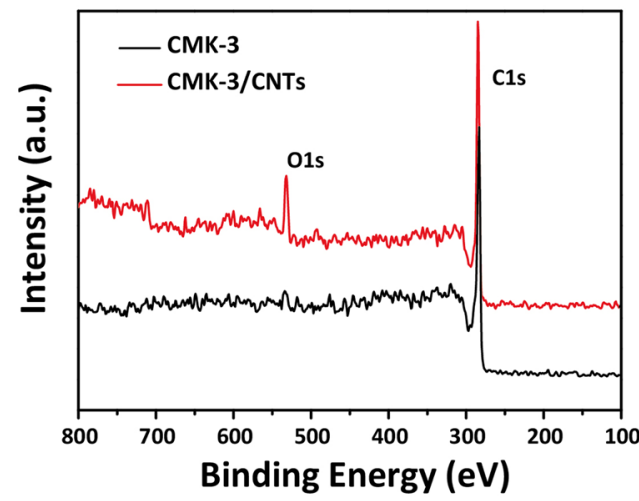

e

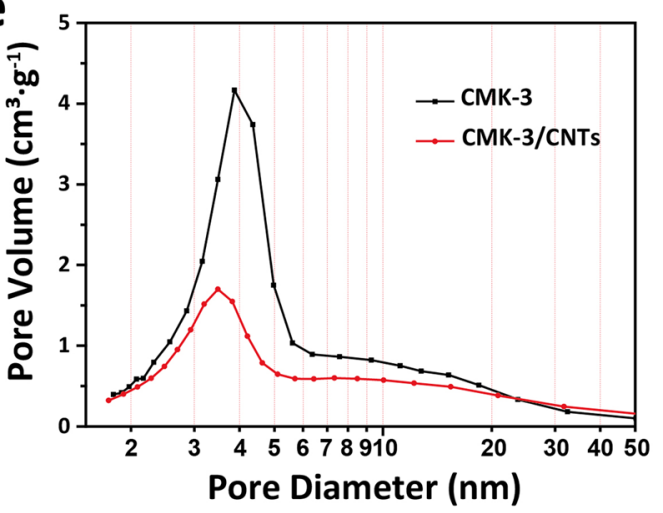

b

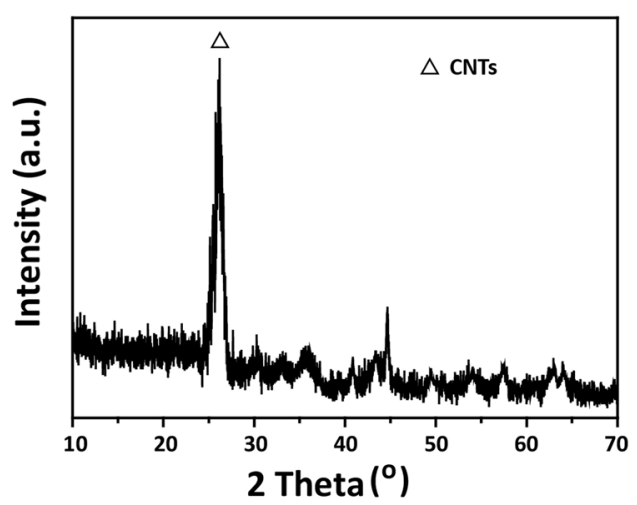

d
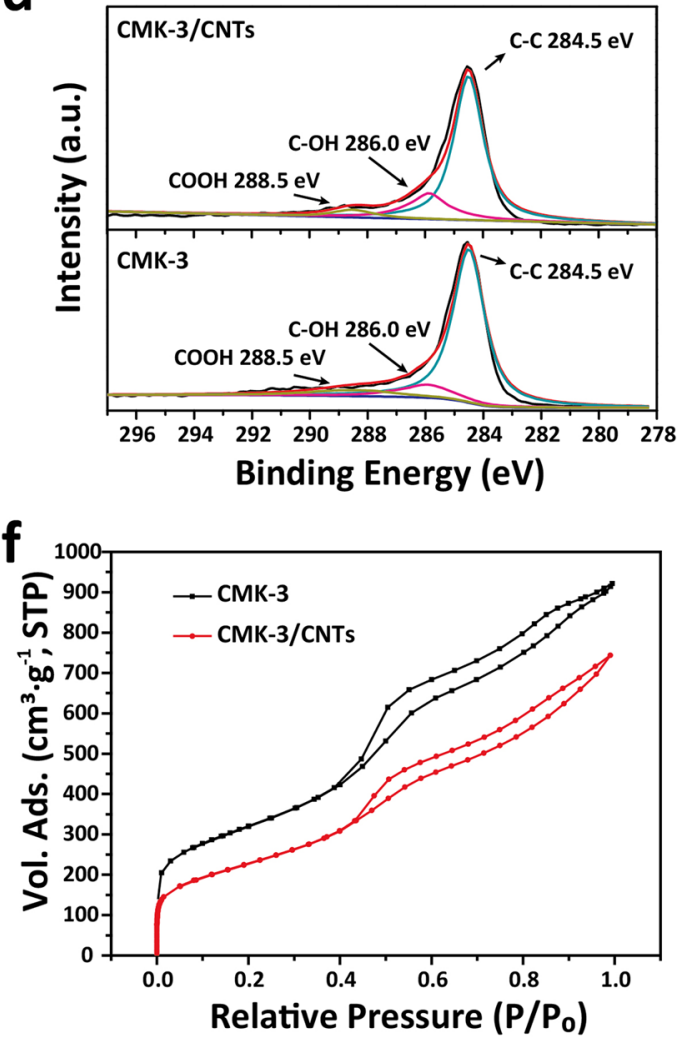

Figure 3. (a) The Raman spectra of the composites with different microwave time; (b) The XRD patterns of the CMK-3/CNTs nanocomposites; (c) Full-range XPS spectra of CMK-3 and CMK-3/CNTs nanocomposites; (d) C 1 s XPS spectra of CMK-3/CNTs nanocomposites and CMK-3 before microwave process. (e) The pore size distributions of CMK-3/CNTs nanocomposites and pristine CMK-3; (f) The N2 adsorption/desorption isotherm curves of CMK-3/CNTs nanocomposites and pristine CMK-3.

showed that as the temperature was lower than $400^{\circ} \mathrm{C}$, the mass of the mixture kept losing for the decomposition of amorphous carbon. The weight loss $(\sim 50 \%)$ observed in the temperature ranging from 400 to $600^{\circ} \mathrm{C}$ is mainly due to the decomposition of CNTs. When the temperature exceeds $600^{\circ} \mathrm{C}$, the weight remains for the little residue of the iron compounds.

Electrochemical performances of CMK-3/CNTs nanocomposites. The electrochemical performances of the microwave-induced CMK-3/CNTs nanocomposites were investigated by cyclic voltammetry $(\mathrm{CV})$, galvanostatic charge/discharge (GCD), and electrochemical impedance spectroscopy (EIS) tests. All the three-electrode tests were performed in $1 \mathrm{M} \mathrm{H}_{2} \mathrm{SO}_{4}$ aqueous solution as the electrolyte. The mass loading of the active materials on the individual electrode was about $5 \mathrm{mg}$.

In the synthesis step, $60 \mathrm{wt} . \%, 70 \mathrm{wt} . \%, 80 \mathrm{wt} . \%, 90 \mathrm{wt} . \%$ and $100 \mathrm{wt} . \%$ ferrocene-saturated benzene solution were marked with CMK-3/CNTs-60\%, CMK-3/CNTs-70\%, CMK-3/CNTs-80\%, CMK-3/CNTs- $90 \%$ and CMK-3/CNTs-100\%. Figure 4a presents the CV curves (capacitance from current divided by the scan rate) of 
a

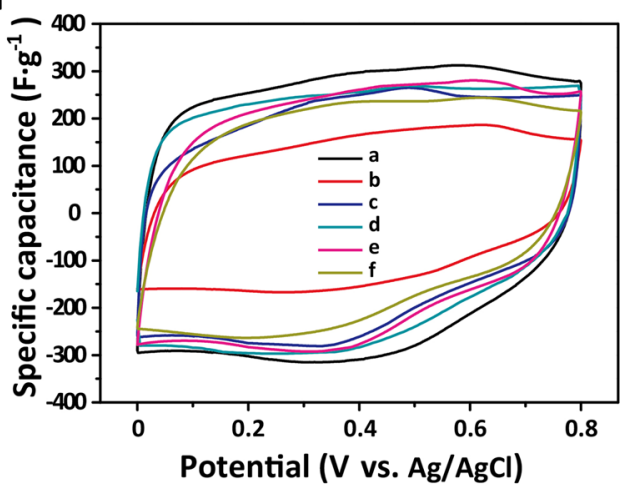

C

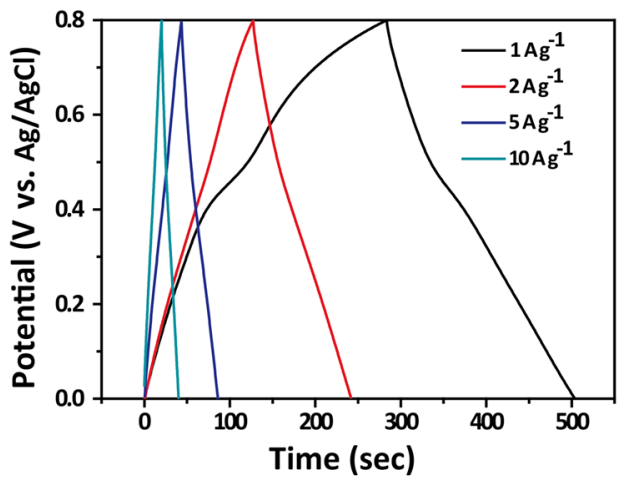

b

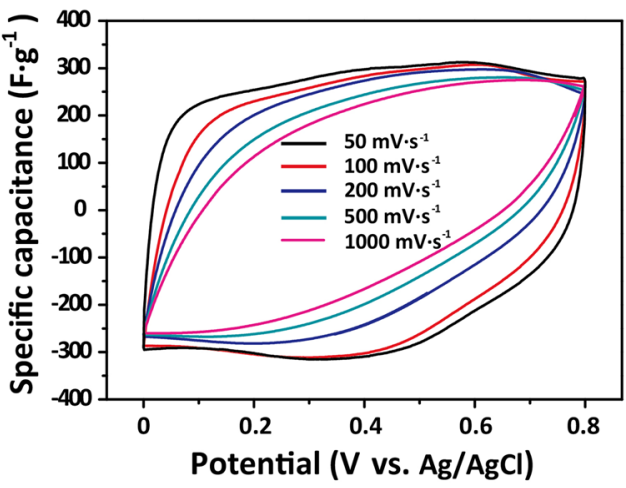

d

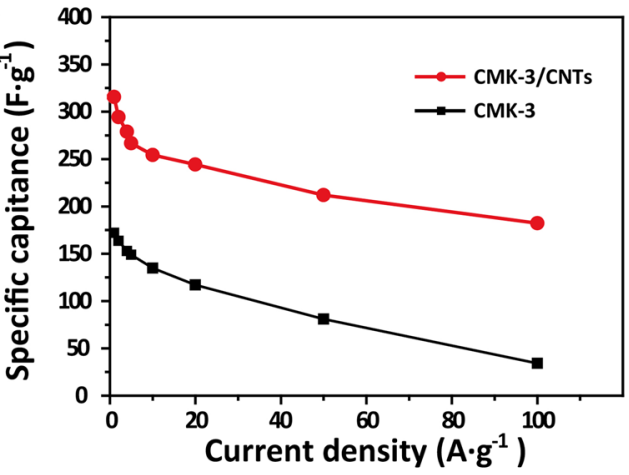

Figure 4. (a) CV curves of CMK-3/CNTs- $\mathrm{x} \%$ at scan rate of $50 \mathrm{mV} \cdot \mathrm{s}-1: \mathbf{a}$. CMK-3/CNTs- $80 \%$, b. pristine CMK-3, c. CMK-3/CNTs-100\%, d. CMK-3/CNTs-90\%, e. CMK-3/CNTs-70\%, f. CMK-3/CNTs-60\%; (b) CV curves of CMK-3/CNTs- $80 \%$ at various scan rate; (c) GCD measurement of CMK-3/CNTs- $80 \%$ at current density ranging from $1 \mathrm{~A} \cdot \mathrm{g}-1$ to $10 \mathrm{~A} \cdot \mathrm{g}-1$; (d) Specific gravimetric capacitance of CMK-3/CNTs- $80 \%$ and pristine CMK-3 at different charge/discharge current densities.

the CMK-3/CNTs-X\% composites at a scan rate of $50 \mathrm{mV} \cdot \mathrm{s}^{-1}$. It demonstrates that the $\mathrm{CV}$ curves are rectangular shapes which are the symbol of EDLCs. It is found from the CV curves that, compared with pristine CMK-3, the CMK-3/CNTs nanocomposites exhibit much enhanced specific capacitance. Among different precursor ferrocene concentrations, CMK-3/CNTs- $80 \%$ exhibits the best electrochemical behavior. The high density of ferrocene would produce an abundant amount of catalyst thus enhancing the CNTs synthesis efficiency but the excessive content of ferrocene may cause the large bulk of Fe particles which hinder the CNTs catalysis process and even cause aggregation to block the nanochannels. After that, we investigated the CV curves of CMK-3/CNTs- $80 \%$ at various scan rates ranging from $50 \mathrm{mV} \cdot \mathrm{s}^{-1}$ to $1000 \mathrm{mV} \cdot \mathrm{s}^{-1}$ as shown in Figure $4 \mathrm{~b}$. The curves remain its shape even at highest scan rates, indicating rapid ion diffusion and electron transport efficiency. The mesopores in CMK-3 were responsible for adsorbing ions from the electrolyte and shortening the ion diffusion pathways. CNTs were utilized to effectively build electrons interconnecting pathways in the nanocomposites thus reducing the internal resistance and enhancing the rate capability. In Figure 4c, GCD measurements at a current density ranging from $1 \mathrm{~A} \cdot \mathrm{g}^{-1}$ to $100 \mathrm{~A} \cdot \mathrm{g}^{-1}$ are given. The galvanostatic charge and discharge curves are nearly symmetric and the charging time is close to the corresponding discharging time. We further calculated the specific capacitance at various current densities shown in Figure $4 \mathrm{~d}$ to analyze the rate capability of CMK-3/CNTs nanocomposites. The specific capacitance maintains $81 \%$ at a current density of $10 \mathrm{~A} \cdot \mathrm{g}^{-1}$ and even $69 \%$ at $50 \mathrm{~A} \cdot \mathrm{g}^{-1}$, indicating the prominent rate performance of CMK-3/CNTs nanocomposites. A comparison of the specific capacitances and rate capabilities of this work with recent work in regard to EDLCs or mesoporous carbon supercapacitors are shown in Table 1. It illustrates the comparable capacitive performance of CMK-3/CNTs nanocomposites in this work.

The EIS measurements of CMK-3/CNTs nanocomposites were performed at a frequency ranging from $0.01 \mathrm{~Hz}$ to $10 \mathrm{kHz}$. It is considered as a powerful complementary technique to investigate interfacial resistance between the electrode and the current collector, the ion adsorption and diffusion resistance and electron transport resistance of the electrode material. Nyquist plots of the CMK-3/CNTs nanocomposites and pristine CMK-3 are shown in Figure 5a. In the low-frequency part, CMK-3/CNTs nanocomposites curve exhibit more straight and vertical line compared with that of pristine CMK-3, indicating higher ion diffusion efficiency as ideal EDLCs. Figure 5b shows the equivalent circuit model of the EDLCs cell in high-frequency and intermediate-frequency part. The CPE represents EDLCs constant phase element and $Z_{\mathrm{w}}$ represents Warburg impedance. The intersection point value of $Z^{\prime}$ axis $\left(\mathrm{R}_{\mathrm{c}}\right)$ is determined by the electrolyte conductivity, the electronic resistance of the electrode and the contact resistance at the interface between active materials and current collectors. $\mathrm{R}_{\mathrm{c}}$ of CMK-3/CNTs nanocomposites is $\sim 1.01 \Omega$ lower than that of pristine CMK-3 $(\sim 1.4 \Omega)$ because the conductive CNTs pinned to and wrapping on the CMK-3 particles facilitate the interfacial electric contact between the electrode material and the current collector $^{58}$. Moreover, the CNTs bridge 3D network with each other and build up additional conducting routes between 


\begin{tabular}{|c|c|c|}
\hline Materials & Specific capacitance & Rate capability \\
\hline This work & $315.6 \mathrm{~F} \cdot \mathrm{g}^{-1}$ at $1 \mathrm{~A} \cdot \mathrm{g}^{-1}$ & $214.6 \mathrm{~F} \cdot \mathrm{g}^{-1}$ at $50 \mathrm{~A} \cdot \mathrm{g}^{-1}(69 \%$ retention $)$ \\
\hline OMC/CNTs nanocomposite $e^{58}$ & $338.1 \mathrm{~F} \cdot \mathrm{g}^{-1}$ at $1 \mathrm{~A} \cdot \mathrm{g}^{-1}$ & $38 \%$ retention at $50 \mathrm{~A} \cdot \mathrm{g}^{-1}$ \\
\hline CNTs and activated high surface area carbon ${ }^{59}$ & $200 \mathrm{~F} \cdot \mathrm{g}^{-1}$ at $1 \mathrm{~A} \cdot \mathrm{g}^{-1}$ & NA \\
\hline Graphene Hydrogels $^{60}$ & $220 \mathrm{~F} \cdot \mathrm{g}^{-1}$ at $1 \mathrm{~A} \cdot \mathrm{g}^{-1}$ & $64 \%$ retention at $100 \mathrm{~A} \cdot \mathrm{g}^{-1}$ \\
\hline Mesoporous carbon spheres/RGO sheets ${ }^{61}$ & $41.5 \mathrm{~F} \cdot \mathrm{g}^{-1}$ at $1 \mathrm{~A} \cdot \mathrm{g}^{-1}$ & $85 \%$ retention at $25 \mathrm{~A} \cdot \mathrm{g}^{-1}$ \\
\hline Flower-like and hierarchical porous carbon materials ${ }^{62}$ & $294 \mathrm{~F} \cdot \mathrm{g}^{-1}$ at a scan rate of $2 \mathrm{mV} \cdot \mathrm{s}^{-1}$ & $71 \%$ retention at $500 \mathrm{mV} \cdot \mathrm{s}^{-1}$ \\
\hline Hollow carbon spheres anchored on carbon nanotubes ${ }^{63}$ & $201.5 \mathrm{~F} \cdot \mathrm{g}^{-1}$ at $0.5 \mathrm{~A} \cdot \mathrm{g}^{-1}$ & $69 \%$ retention at $20 \mathrm{~A} \cdot \mathrm{g}^{-1}$ \\
\hline
\end{tabular}

Table 1. The specific capacitances and rate capabilities of this work compared with other work about EDLCs or mesoporous carbon supercapacitors.

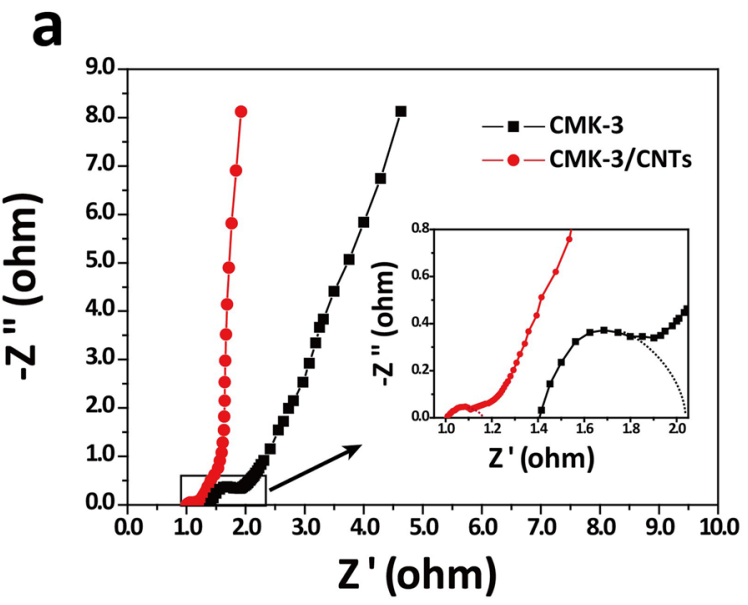

b

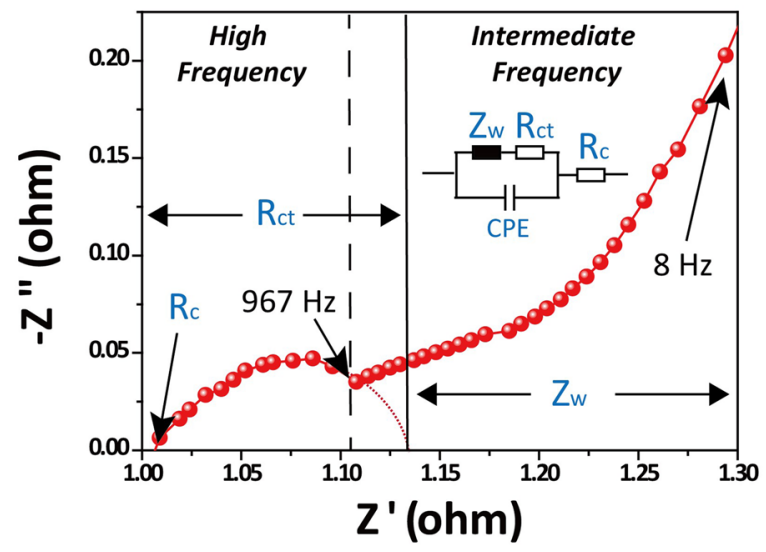

Figure 5. (a) Nyquist plots of the CMK-3/CNTs nanocomposites and pristine CMK-3; Inset, the expanded image of their high-frequency region; (b) Nyquist plots of the CMK-3/CNTs nanocomposites and equivalent circuit model of the EDLCs electrodes.

CMK-3 particles thus reducing the charge transfer resistance $\left(\mathrm{R}_{\mathrm{ct}}\right)$. Semi-circle diameter at high-frequency part is a symbol of charge transfer resistance $\left(\mathrm{R}_{\mathrm{ct}}\right)$ and the specimens of CMK-3/CNTs nanocomposites have lower $\mathrm{R}_{\mathrm{ct}}$ $(\sim 0.12 \Omega)$ compared with pristine CMK-3 $(\sim 0.62 \Omega)$ indicating evidently enhanced electrical connection between well-ordered mesoporous structures. As a result, more efficient ions adsorption/diffusion and faster charge transport between the CMK-3 particles give rise to the improved electrochemical performances of CMK-3/CNTs nanocomposites. Comparison of as-synthesized CMK-3/CNTs nanocomposites with prstine CMK-3 as electrode materials are shown in Table 2.

The cycle life of CMK-3/CNTs nanocomposites was tested at a current density of $10 \mathrm{~A} \cdot \mathrm{g}^{-1}$ to investigate its capacitance stability through the repeatedly charging-discharging process. After 5000 cycles, the capacitance retention was $96.8 \%$ as shown in Fig. S7. The slight increase of capacitance to $102.5 \%$ could be contributed by the activation process by acid electrolyte gradually infiltrated into all accessible mesoporous structures ${ }^{64}$. The degradation of the functional groups and dissolved oxygen in the electrolyte might lead to the slight loss of capacitance. 


\begin{tabular}{|l|l|l|l|l|l|l|}
\hline Sample & $\boldsymbol{S}_{\text {BET }}{ }^{\mathbf{a}}\left(\mathrm{cm}^{2} \cdot \mathbf{g}^{-1}\right)$ & $\boldsymbol{a}^{\mathbf{b}}(\mathbf{n m})$ & $\boldsymbol{R}_{c}{ }^{\mathrm{c}}(\mathbf{o h m})$ & $\boldsymbol{R}_{c t}{ }^{\mathrm{d}}(\mathbf{o h m})$ & $\boldsymbol{C}_{m}{ }^{\mathrm{e}}\left(\mathbf{F} \cdot \mathrm{g}^{-1}\right)$ & $E^{\mathrm{f}}\left(\mathbf{W h} \cdot \mathrm{kg}^{-1}\right)$ \\
\hline CMK-3 & 1109 & 11.3 & 1.40 & 0.62 & 172.1 & 12.1 \\
\hline CMK-3/CNTs & 801 & 11.3 & 1.01 & 0.12 & 315.6 & 21.7 \\
\hline
\end{tabular}

Table 2. Comparison of as-synthesized CMK-3/CNTs nanocomposites with CMK-3. aSurface area calculated by the (Brunauer-Emmett-Teller) BET method ${ }^{\mathrm{b} C e l l}$ parameters ${ }^{\mathrm{C}}$ Intersection point value of $\mathrm{Z}^{\prime}$ axis ${ }^{\mathrm{d}} \mathrm{Charge}$ transfer resistance ${ }^{\mathrm{e}}$ Specific capacitance at a current density of $1 \mathrm{~A} \cdot \mathrm{g}^{-1 \mathrm{f}}$ Energy density at a current density of $0.5 \mathrm{~A} \cdot \mathrm{g}^{-1}$

Despite that, the nanocomposites showed remarkable cycling stability which corresponds to the inherent advantage of carbon-based electric double-layer supercapacitors.

Electrochemical performances of CMK-3/CNTs symmetric EDLCs. To further investigate the superior properties of the CMK-3/CNTs nanocomposites, symmetric electrodes EDLCs cell were assembled and $1 \mathrm{M} \mathrm{Na}_{2} \mathrm{SO}_{4}$ aqueous solution was applied as the neutral electrolyte. The higher operating voltage window could be reached in $\mathrm{Na}_{2} \mathrm{SO}_{4}$ aqueous electrolyte due to over-potential for hydrogen evolution. As is shown in Figure $6 \mathrm{a}$, expanded voltage range of $0-1.6 \mathrm{~V}$ was conducted, the $\mathrm{CV}$ curves kept rectangular shape at a scan rate of $20 \mathrm{mV} \cdot \mathrm{s}^{-1}$, suggesting ideal EDLCs behavior. But $0-1.8 \mathrm{~V}$ voltage would result in sharp current density increase due to the polarization of electrode and decomposition of electrolyte in the charge/discharge process. $\mathrm{CV}$ curves of the symmetric EDLCs cell were attained at scan rates from $50-1000 \mathrm{mV} \cdot \mathrm{s}^{-1}$ in the voltage range of $0-1.8 \mathrm{~V}$ (Figure 6b). As is shown in Figure $6 \mathrm{c}$, GCD measurement at a current density ranging from $0.5 \mathrm{~A} \cdot \mathrm{g}^{-1}$ to $10 \mathrm{~A} \cdot \mathrm{g}^{-1}$ indicated symmetric charge/discharge time and no obvious polarization or IR drop at $1.8 \mathrm{~V}$. The specific capacitance of single electrode $\left(C_{s p}\right)$ in symmetric EDLCs cell were calculated and shown in Figure $6 \mathrm{~d}$. $C_{s p}$ of $243.81 \mathrm{~F} \cdot \mathrm{g}^{-1}$ at $0.5 \mathrm{~A} \cdot \mathrm{g}^{-1}$ and $119.18 \mathrm{~F} \cdot \mathrm{g}^{-1}$ at $50 \mathrm{~A} \cdot \mathrm{g}^{-1}$ suggest good rate capability of the symmetric cell due to rapid ion diffusion and charge transport of the CMK-3/CNTs electrode. In Figure 6e, Nyquist plots at the low and high-frequency region of the symmetric EDLCs cell were obtained. Compared with pristine CMK-3 electrodes symmetric cell, CMK-3/CNTs nanocomposites electrodes symmetric cell showed decreased internal resistance and enhanced charge transport efficiency. Ragone plots of the cell shown in Figure $6 \mathrm{f}$ demonstrate superior specific energy and power densities values of CMK-3/CNTs nanocomposites symmetric EDLCs cell, compared with previously reported literature of carbon-based composites, porous carbon and CNTs as electrodes ${ }^{59-61,65-71}$.

The capacitance retention and the Coulombic efficiency of the symmetric EDLCs cell were measured at charge/discharge current density of $10 \mathrm{~A} \cdot \mathrm{g}^{-1}$ for more than 10,000 cycles. As is shown in Figure 7, long-term stability was demonstrated that the Coulombic efficiency keeps around $100 \%$ and the capacitance remains $\sim 99.32 \%$ after 10, 000 cycles. In addition, the pore and channel size of CMK-3 is also editable by controlling the reaction temperature during the synthesis process of SBA- 15 or by adding boric acid during the CMK-3 synthesis process (see Supplementary Information), to meet extensive application requirements of active materials for energy storage and catalysis. We made a prototype symmetric supercapacitor with as-synthesized CMK-3/CNTs composites as electrodes to power a red light-emitting diodes (LED) light. The schematic illustration and photograph of the supercapacitor prototype were shown in Fig. S8.

\section{Conclusions}

In conclusion, rambutan-like CMK-3/CNTs nanocomposites were synthesized by an ultrafast microwave heating approach for the first time. A 10-30 seconds' microwave heating was conducted to catalyze in-suit CNTs growth within the nanochannel of CMK-3. As-synthesized CNTs interconnecting between mesoporous CMK-3 particles can efficiently bridge $3 \mathrm{D}$ conducting networks. This characteristic structure contributed to the promotion of electron transport efficiency, pore connectivity and effective surface area for ion adsorption and diffusion. Therefore, the CMK-3/CNTs electrodes demonstrated superior electric double-layer capacitive performance, such as enhanced specific capacitance $\left(315.6 \mathrm{~F} \cdot \mathrm{g}^{-1}\right.$ at $1 \mathrm{~A} \cdot \mathrm{g}^{-1}$, as compared with $172.1 \mathrm{~F} \cdot \mathrm{g}^{-1}$ of pristine CMK-3), high rate capability $\left(214.6 \mathrm{~F} \cdot \mathrm{g}^{-1}\right.$ at $\left.50 \mathrm{~A} \cdot \mathrm{g}^{-1}\right)$ and excellent cycling stability ( $99.32 \%$ after $\left.10,000 \mathrm{cycles}\right)$. In the 2-electrode system, as-made symmetric electrodes cell demonstrated exceptionally high energy density and high power density along with long and stable cycle life. The microwave synthesis approach of CMK-3/CNTs nanocomposites shows great potential for ultrafast, easy and relatively low-cost production of the high-performance carbon-based electrode material for supercapacitors. We also envision our microwave approach as a time- and energy-saving method for varieties of high property nanocomposite materials' synthesis and production which would have promising applications in energy storage, sensors, catalysis, etc.

\section{Methods}

Microwave synthesis of CMK-3/carbon nanotubes nanocomposites. In a typical process, $0.01 \mathrm{~g}$ CMK-3 powder (purchased from XF Nano, China) (typical synthesis process shown in Supplementary Information) were added into $5 \mathrm{~mL} 80 \mathrm{wt} \%$ saturated solution of ferrocene (99.5\%, Alfa Aesar) in benzene (99.5\%, Shanghai Lingfeng) followed by 6 hrs of stirring using a magnetic stirrer and then stand still for another 6 hrs to let ferrocene fill in the nanochannels of CMK-3 by capillary force. After removal of redundant upper liquid, the mixture was placed in a quartz boat for air dry at room temperature for $24 \mathrm{hrs}$. Subsequently, a 30-seconds microwave process with the power of $700 \mathrm{~W}$ was applied to heat the precursor by a household microwave heater (Galanz P70D20TP-C6, China) and under ambient condition. It was observed that continuous arcs and sparks appeared on the surface of the precursor with the temperature rising rapidly. After obtaining relatively fluffy black 
a

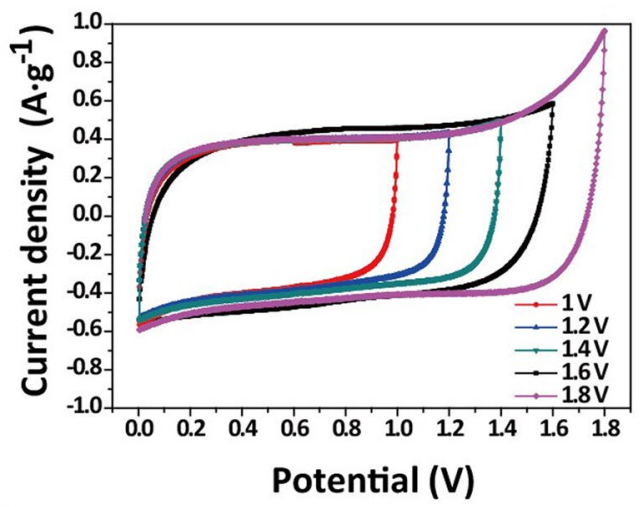

C

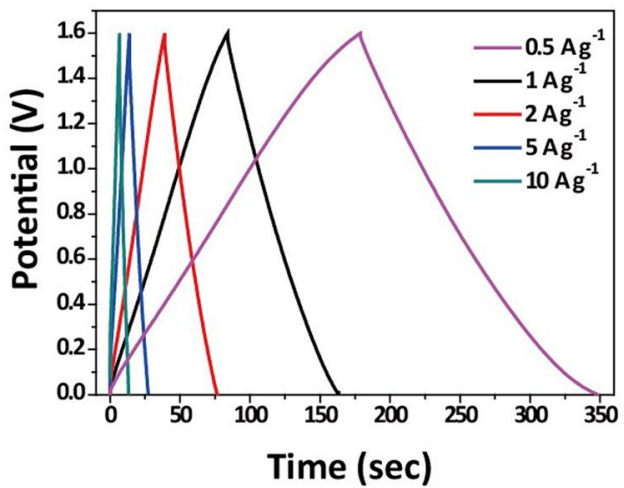

$\mathbf{e}$

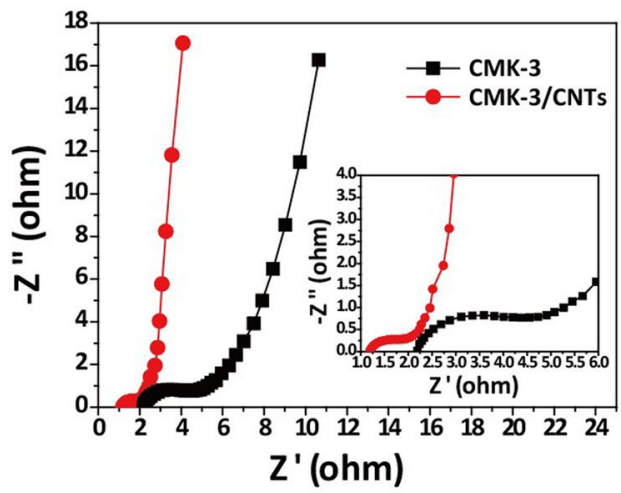

b

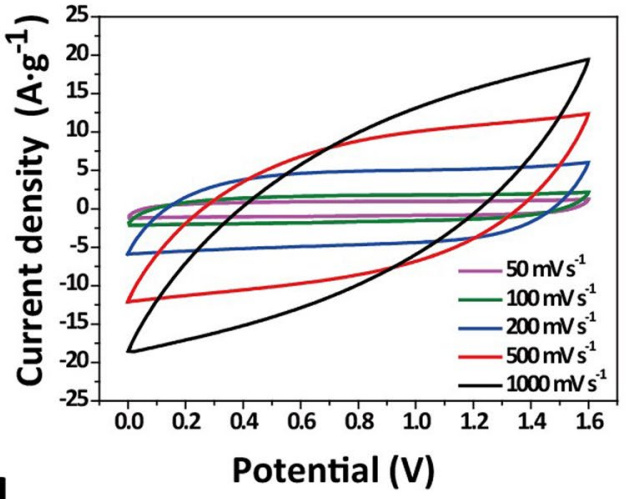

d

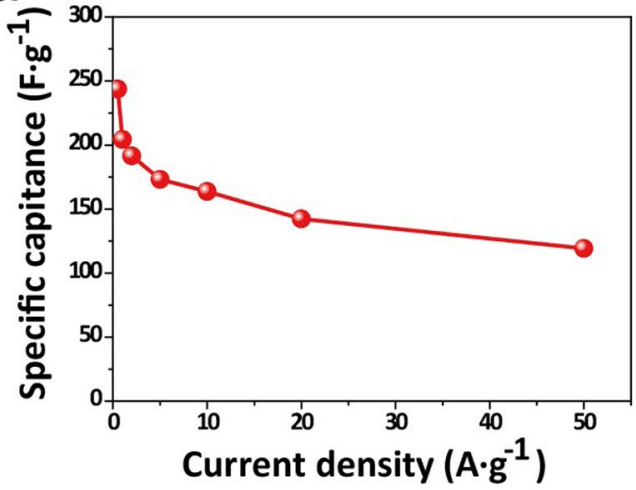

$f$

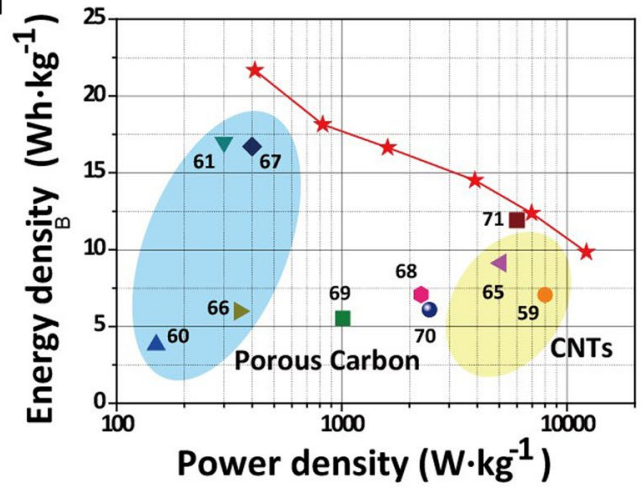

Figure 6. Electrochemical performance of CMK-3/CNTs nanocomposites symmetric EDLCs cell in a twoelectrode system (1 M Na2SO4 as aqueous electrolytes at room temperature): (a) CV curves of the symmetric EDLCs cell at different operation voltage windows (scan rate $20 \mathrm{mV} \cdot \mathrm{s}-1$ ); (b) CV curves of the symmetric EDLCs cell at different scan rates; (c) GCD measurement of the symmetric EDLCs cell at different charge/ discharge current densities; (d) The specific capacitance versus different charge/discharge current densities; (e) Nyquist plots of the CMK-3/CNTs and pristine CMK-3 based symmetric EDLCs cell; Inset, magnification of the high-frequency region; (f) Ragone plots of the symmetric EDLCs cell and comparison with recently reported high-performance symmetric supercapacitors in aqueous electrolyte.

powder, purification was conducted by washing it with benzene, acid treatment with $\mathrm{HCl}$ solution $(\sim 37 \mathrm{wt} . \%)$ and then washing it by deionized water until the $\mathrm{pH}$ reached 7. Finally, the CMK-3/CNTs nanocomposites were gained after dried in vacuum at $60^{\circ} \mathrm{C}$ overnight. In electrochemical measurement, $60 \mathrm{wt} \%, 70 \mathrm{wt} . \%, 80 \mathrm{wt} . \%, 90$ wt.\% and $100 \mathrm{wt} . \%$ ferrocene-saturated benzene solution were used in the initial synthesis step, and the other conditions remained unchanged.

Characterization and measurement. Thermal imaging was performed with Fotric-222s thermal imager. Scanning electron microscopy (SEM) was carried out by a JSM-7000F and transmission electron microscopy (TEM) was performed using a JEM-200CX. Thermogravimetric analysis (TGA) and differential scanning calorimetry (DSC) measurement were carried out in a temperature range of $20-1000^{\circ} \mathrm{C}$ in air with a heating rate 


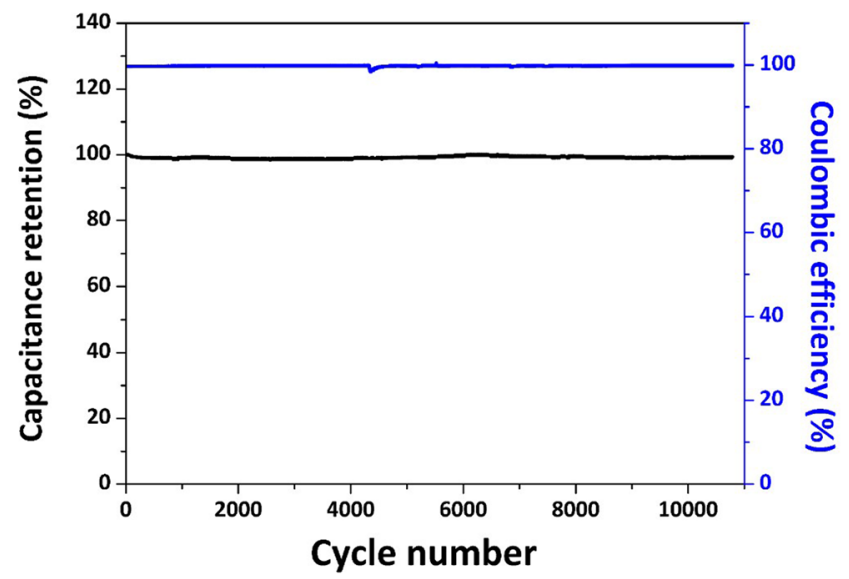

Figure 7. Cycling performance of symmetric EDLCs cell based on CMK-3/CNTs nanocomposites in a twoelectrode system at current density of $10 \mathrm{~A} \cdot \mathrm{g}-1$.

of $10^{\circ} \mathrm{C} \cdot \mathrm{min}^{-1}$ using a Pyris 1 DSC thermal analyzer. Powder X-ray diffraction (XRD) analysis was conducted in an X'TRA with $\mathrm{Cu} \mathrm{K \alpha}$ radiation from $3^{\circ}$ to $70^{\circ}$ at a step size of $0.02^{\circ}$ to inspect the crystalline morphology. Small-angle X-ray scattering (SAXS) was conducted a by SAXSLAB Ganesha model with sample-to-detector distance from $100 \mathrm{~mm}$ to $1500 \mathrm{~mm}$. Raman spectra were analyzed using a DU420A-0E-325, HORIBA Jobin Yvan. X-ray photoelectron spectroscopy (XPS) was measured on the PHI 5000 Versa Probe. Nitrogen adsorption-desorption isotherms were collected at $77 \mathrm{~K}$ using an ASAP 2020. The Brunauer-Emmett-Teller (BET) method was utilized to calculate the specific area and the pore volume. The pore size distribution was analyzed by the Barrett-Joyner-Halenda (BJH) method. Atomic Absorption Spectroscopy (AAS) was measured by a Hitachi 180-80.

Electrochemical measurement. The electrochemical measurements were conducted on a CHI660C electrochemical workstation (Shanghai Chenhua Instrument Corporation, China). In a three-electrode system, the individual electrode was tested using $1 \mathrm{M} \mathrm{H}_{2} \mathrm{SO}_{4}$ aqueous solution as the electrolyte. The potentials were measured using $\mathrm{Ag} / \mathrm{AgCl}$ (in sat. $\mathrm{KCl}$ ) as the reference electrode and $\mathrm{Pt}$ wire as a counter electrode, respectively. The working electrodes were made with $1 \mathrm{~cm} \times 1 \mathrm{~cm}$ carbon cloths as current collectors. A certain amount of as-prepared CMK-3/CNTs nanocomposites was added into isopropanol and then ultrasonicated for $15 \mathrm{~min}$ to promote homogeneity. The slurry was then coated onto the carbon cloth current collector and then dried at $80^{\circ} \mathrm{C}$ for $6 \mathrm{hrs}$ to get the working electrode. Cyclic voltammetry (CV) and galvanostatic charge/discharge (GCD) measurements were conducted at various scan rates in the potential ranging from 0 to $0.8 \mathrm{~V}$. The electrochemical impedance spectroscopy (EIS) were measured in frequency loop ranged from $0.01 \mathrm{~Hz}$ to $10 \mathrm{kHz}$ with a voltage amplitude of $5 \mathrm{mV}$. The cycling stability was tested at a current density of $10 \mathrm{~A} \cdot \mathrm{g}^{-1}$ for $5000 \mathrm{charging} / \mathrm{discharging}$ cycles. $C_{m}$ (denotes the specific capacitances) were calculated according to the equation:

$$
C_{m}=\frac{I \times \Delta t}{m \times \Delta V}
$$

Where $I, m, \Delta V$ and $\Delta t$ represent the charge/discharge current, the mass of the active materials in the single electrode (for the three-electrode system) and mass in both electrodes (for the two-electrode system), the potential window and the discharge time in the corresponding potential window, respectively.

In a two-electrode configuration, the symmetric EDLCs cell was fabricated by assembling two individual electrodes with the same mass loading of active materials. The potential that was applied to the EDLCs cell ranged from 0 to $1.6 \mathrm{~V}$ in $1 \mathrm{M} \mathrm{Na}_{2} \mathrm{SO}_{4}$ aqueous solution as the electrolyte.

According to the CV curves and the specific capacitance of EDLCs cell, $E$ (energy density) and $P$ (power density) of the symmetric EDLCs cell were calculated according to the equation:

$$
\begin{gathered}
C_{s p}=4 \times C_{m} \\
E=\frac{0.5 \times C_{m} \times \Delta V^{2}}{3.6} \\
P=\frac{E}{\Delta t} \times 3600
\end{gathered}
$$

Where $C_{s p}$ represents the specific capacitance of single electrode in the two-electrode cell, $C_{m}$ is calculated as previously mentioned. $\Delta V$ denotes the corresponding potential window except for IR drop in the discharge process and $\Delta t$ is the discharge time in the potential window. 
Received: 22 July 2019; Accepted: 6 March 2020;

Published online: 10 April 2020

\section{References}

1. Della, R. M. \& Rand, D. A. J. Energy storage - a key technology for global energy sustainability. J. Power Sources 100, $2-17$ (2001).

2. Titirici, M. M. et al. Sustainable carbon materials. Chem. Soc. Rev. 44, 250-290 (2015).

3. Salanne, M. et al. Efficient storage mechanisms for building better supercapacitors. Nat Energy 1, 16070 (2016).

4. González, A., Goikolea, E., Barrena, J. A. \& Mysyk, R. Review on supercapacitors: Technologies and materials. Renewable Sustainable Energy Rev. 58, 1189-1206 (2016).

5. Wang, G., Zhang, L. \& Zhang, J. A review of electrode materials for electrochemical supercapacitors. Chem. Soc. Rev. 41, 797-828 (2012).

6. Wang, F. et al. Latest advances in supercapacitors: from new electrode materials to novel device designs. Chem. Soc. Rev. 46, 6816-6854 (2017).

7. Simon, P., Gogotsi, Y. \& Dunn, B. Materials science. Where do batteries end and supercapacitors begin? Science 343, 1210-1211 (2014).

8. Choi, N. S. et al. Challenges facing lithium batteries and electrical double-layer capacitors. Angew. Chem., Int. Ed. Engl. 51, 9994-10024 (2012).

9. Shi, Y. et al. Nanostructured conductive polypyrrole hydrogels as high-performance, flexible supercapacitor electrodes. J. Mater. Chem. A 2, 6086-6091 (2014).

10. Peng, X., Peng, L., Wu, C. \& Xie, Y. Two dimensional nanomaterials for flexible supercapacitors. Chem. Soc. Rev. 43, 3303-3323 (2014).

11. Aravindan, V. et al. Hybrid supercapacitor with nano-TiP2O7 as intercalation electrode. J. Power Sources 196, 8850-8854 (2011).

12. An, G.-H., Ahn, H.-J. \& Hong, W.-K. Electrochemical properties for high surface area and improved electrical conductivity of platinum-embedded porous carbon nanofibers. J. Power Sources 274, 536-541 (2015).

13. Zhuang, Z., Wang, F., Naidu, R. \& Chen, Z. Biosynthesis of Pd-Au alloys on carbon fiber paper: Towards an eco-friendly solution for catalysts fabrication. J. Power Sources 291, 132-137 (2015).

14. Borenstein, A. et al. Carbon-based composite materials for supercapacitor electrodes: a review. J. Mater. Chem. A 5, 12653-12672 (2017).

15. Beguin, F., Presser, V., Balducci, A. \& Frackowiak, E. Carbons and electrolytes for advanced supercapacitors. Adv. Mater. 26(22192251), 2283 (2014).

16. Li, X. \& Wei, B. Supercapacitors based on nanostructured carbon. Nano Energy 2, 159-173 (2013).

17. Yu, M. et al. Boosting the Energy Density of Carbon-Based Aqueous Supercapacitors by Optimizing the Surface Charge. Angew. Chem., Int. Ed. Engl. 129, 5546-5551 (2017).

18. Zhou, J. et al. Nitrogen-doped highly dense but porous carbon microspheres with ultrahigh volumetric capacitance and rate capability for supercapacitors. J. Mater. Chem. A 7, 476-485 (2019).

19. Chen, L.-F., Lu, Y., Yu, L. \& Lou, X. W. Designed formation of hollow particle-based nitrogen-doped carbon nanofibers for highperformance supercapacitors. Energy Environ. Sci. 10, 1777-1783 (2017).

20. Portet, C., Yushin, G. \& Gogotsi, Y. Electrochemical performance of carbon onions, nanodiamonds, carbon black and multiwalled nanotubes in electrical double layer capacitors. Carbon 45, 2511-2518 (2007).

21. Chen, Z. et al. High-performance supercapacitors based on intertwined CNT/V2O5 nanowire nanocomposites. Adv. Mater. 23, 791-795 (2011)

22. Chen, C. et al. All-wood, low tortuosity, aqueous, biodegradable supercapacitors with ultra-high capacitance. Energy Environ. Sci. 10, 538-545 (2017).

23. Chen, Z. et al. A Three-Dimensionally Interconnected Carbon Nanotube-Conducting Polymer Hydrogel Network for HighPerformance Flexible Battery Electrodes. Adv. Energy Mater. 4, 1400207 (2014).

24. Lv, Z. et al. Honeycomb-Lantern-Inspired 3D Stretchable Supercapacitors with Enhanced Specific Areal Capacitance. Adv. Mater. 30, e1805468 (2018).

25. Wang, Y. \& Xia, Y. Recent progress in supercapacitors: from materials design to system construction. Adv. Mater. 25, 5336-5342 (2013).

26. Li, H.-Q., Luo, J.-Y., Zhou, X.-F., Yu, C.-Z. \& Xia, Y.-Y. An Ordered Mesoporous Carbon with Short Pore Length and Its Electrochemical Performances in Supercapacitor Applications. J. Electrochem. Soc. 154, A731 (2007).

27. Xia, K., Gao, Q., Jiang, J. \& Hu, J. Hierarchical porous carbons with controlled micropores and mesopores for supercapacitor electrode materials. Carbon 46, 1718-1726 (2008).

28. Qie, L. et al. Synthesis of functionalized 3D hierarchical porous carbon for high-performance supercapacitors. Energy Environ. Sci. 6, 2497 (2013).

29. Pandolfo, A. G. \& Hollenkamp, A. F. Carbon properties and their role in supercapacitors. J. Power Sources 157, 11-27 (2006).

30. Frackowiak, E. \& Béguin, F. Carbon materials for the electrochemical storage of energy in capacitors. Carbon 39, 937-950 (2001).

31. De Volder, M. F., Tawfick, S. H., Baughman, R. H. \& Hart, A. J. Carbon nanotubes: present and future commercial applications. Science 339, 535-539 (2013).

32. Zhi, M., Xiang, C., Li, J., Li, M. \& Wu, N. Nanostructured carbon-metal oxide composite electrodes for supercapacitors: a review. Nanoscale 5, 72-88 (2013).

33. Yoo, Y., Kim, M.-S., Kim, J.-K., Kim, Y. S. \& Kim, W. Fast-response supercapacitors with graphitic ordered mesoporous carbons and carbon nanotubes for AC line filtering. J. Mater. Chem. A 4, 5062-5068 (2016).

34. Cheon, J. Y. et al. Ordered mesoporous carbon-carbon nanotube nanocomposites as highly conductive and durable cathode catalyst supports for polymer electrolyte fuel cells. J. Mater. Chem. A 1, 1270-1283 (2013).

35. Jo, Y. et al. Highly interconnected ordered mesoporous carbon-carbon nanotube nanocomposites: Pt-free, highly efficient, and durable counter electrodes for dye-sensitized solar cells. Chem. Commun. 48, 8057-8059 (2012).

36. Su, F., Zhao, X. S., Wang, Y. \& Lee, J. Y. Bridging mesoporous carbon particles with carbon nanotubes. Microporous Mesoporous Mater. 98, 323-329 (2007).

37. Kitchen, H. J. et al. Modern microwave methods in solid-state inorganic materials chemistry: from fundamentals to manufacturing. Chem. Rev. 114, 1170-1206 (2014).

38. Kappe, C. O. Controlled microwave heating in modern organic synthesis. Angew. Chem., Int. Ed. Engl. 43, 6250-6284 (2004).

39. Schwenke, A. M., Hoeppener, S. \& Schubert, U. S. Microwave synthesis of carbon nanofibers - the influence of MW irradiation power, time, and the amount of catalyst. J. Mater. Chem. A 3,23778-23787 (2015).

40. Zhang, X. \& Manohar, S. K. Microwave synthesis of nanocarbons from conducting polymers. Chem. Commun. 23, 2477-2479 (2006).

41. Liu, Z. et al. Poptube approach for ultrafast carbon nanotube growth. Chem. Commun. 47, 9912-9914 (2011).

42. Hsin, Y. L. et al. Microwave Arcing Induced Formation and Growth Mechanisms of Core/Shell Metal/Carbon Nanoparticles in Organic Solutions. Adv. Funct. Mater. 18, 2048-2056 (2008). 
43. Zhan, M., Pan, G., Wang, Y., Kuang, T. \& Zhou, F. Ultrafast carbon nanotube growth by microwave irradiation. Diamond Relat. Mater. 77, 65-71 (2017)

44. Bajpai, R. \& Wagner, H. D. Fast growth of carbon nanotubes using a microwave oven. Carbon 82, 327-336 (2015).

45. Schwenke, A. M., Hoeppener, S. \& Schubert, U. S. Synthesis and Modification of Carbon Nanomaterials utilizing Microwave Heating. Adv. Mater. 27, 4113-4141 (2015).

46. Robinson, J. et al. Understanding microwave heating effects in single mode type cavities-theory and experiment. Phys. Chem. Chem. Phys. 12, 4750-4758 (2010).

47. Rao, K. J., Vaidhyanathan, B., Ganguli, M. \& Ramakrishnan, P. A. Synthesis of Inorganic Solids Using Microwaves. Chem. Mater. 11, 882-895 (1999).

48. Liu, Z. et al. An ultrafast microwave approach towards multi-component and multi-dimensional nanomaterials. RSC Adv. 4, 9308 (2014).

49. Liu, Q. et al. Direct synthesis of carbon nanotubes decorated with size-controllable Fe nanoparticles encapsulated by graphitic layers. Carbon 46, 1417-1423 (2008).

50. Liu, Q. et al. Synthesis of different magnetic carbon nanostructures by the pyrolysis of ferrocene at different sublimation temperatures. Carbon 46, 1892-1902 (2008).

51. Su, H.-C. et al. Improving the adhesion of carbon nanotubes to a substrate using microwave treatment. Carbon 48, 805-812 (2010).

52. Kim, N. S. et al. Vertically Aligned Carbon Nanotubes Grown by Pyrolysis of Iron, Cobalt, and Nickel Phthalocyanines. J. Phys. Chem. B 107, 9249-9255 (2003).

53. Yamashita, T. \& Hayes, P. Analysis of XPS spectra of Fe2+ and Fe3+ ions in oxide materials. Appl. Surf. Sci. 254, 2441-2449 (2008).

54. Lee, W. H. \& Reucroft, P. J. Vapor adsorption on coal- and wood-based chemically activated carbons. Carbon 37, 7-14 (1999).

55. Sangwichien, C., Aranovich, G. L. \& Donohue, M. D. Density functional theory predictions of adsorption isotherms with hysteresis loops. Colloids Surf., A 206, 313-320 (2002).

56. Barbieri, O., Hahn, M., Herzog, A. \& Kötz, R. Capacitance limits of high surface area activated carbons for double layer capacitors. Carbon 43, 1303-1310 (2005).

57. Saremi-Yarahmadi, S., Tahir, A. A., Vaidhyanathan, B. \& Wijayantha, K. G. U. Fabrication of nanostructured $\alpha-\mathrm{Fe} 2 \mathrm{O} 3$ electrodes using ferrocene for solar hydrogen generation. Mater. Lett. 63, 523-526 (2009).

58. Zhu, Z., Hu, Y., Jiang, H. \& Li, C. A three-dimensional ordered mesoporous carbon/carbon nanotubes nanocomposites for supercapacitors. J. Power Sources 246, 402-408 (2014).

59. Noked, M., Okashy, S., Zimrin, T. \& Aurbach, D. Composite carbon nanotube/carbon electrodes for electrical double-layer super capacitors. Angew. Chem., Int. Ed. Engl. 51, 1568-1571 (2012).

60. Zhang, L. \& Shi, G. Preparation of Highly Conductive Graphene Hydrogels for Fabricating Supercapacitors with High Rate Capability. J. Phys. Chem. C 115, 17206-17212 (2011).

61. Lei, Z. B., Christov, N. \& Zhao, X. S. Intercalation of mesoporous carbon spheres between reduced graphene oxide sheets for preparing high-rate supercapacitor electrodes. Energy Environ. Sci. 4, 1866-1873 (2011)

62. Wang, Q. et al. Three-dimensional flower-like and hierarchical porous carbon materials as high-rate performance electrodes for supercapacitors. Carbon 67, 119-127 (2014).

63. Wang, Q. et al. Template synthesis of hollow carbon spheres anchored on carbon nanotubes for high rate performance supercapacitors. Carbon 52, 209-218 (2013).

64. Wang, D., Geng, Z., Li, B. \& Zhang, C. High performance electrode materials for electric double-layer capacitors based on biomassderived activated carbons. Electrochim. Acta 173, 377-384 (2015).

65. Huang, C.-W., Hsieh, C.-T., Kuo, P.-L. \& Teng, H. Electric double layer capacitors based on a composite electrode of activated mesophase pitch and carbon nanotubes. J. Mater. Chem. 22, 7314 (2012).

66. Zheng, C., Qi, L., Yoshio, M. \& Wang, H. Cooperation of micro- and meso-porous carbon electrode materials in electric doublelayer capacitors. J. Power Sources 195, 4406-4409 (2010).

67. Li, Y., Wang, G., Wei, T., Fan, Z. \& Yan, P. Nitrogen and sulfur co-doped porous carbon nanosheets derived from willow catkin for supercapacitors. Nano Energy 19, 165-175 (2016).

68. Kim, T. Y. et al. High-performance supercapacitors based on poly(ionic liquid)-modified graphene electrodes. ACS Nano 5, 436-442 (2011).

69. Lee, J. H. et al. Restacking-inhibited 3D reduced graphene oxide for high performance supercapacitor electrodes. ACS Nano 7, 9366-9374 (2013).

70. Xu, Y. et al. Flexible solid-state supercapacitors based on three-dimensional graphene hydrogel films. ACS Nano 7, 4042-4049 (2013).

71. Tang, J. et al. Activated Porous Carbon Spheres with Customized Mesopores through Assembly of Diblock Copolymers for Electrochemical Capacitor. ACS Appl Mater Interfaces 9, 18986-18993 (2017).

\section{Acknowledgements}

The authors are thankful for financial support from the National Natural Science Foundation of China (61825403, 61674078, 61229401, 41401257, 1157436), the Chinese National Key Fundamental Research Project (2017YFA0206302), and the PAPD program.

\section{Author contributions}

L.P. supervised and guided all aspects of the project. K.Y. synthesized materials, prepared the samples, and carried out experiments. L.P. and X.S. designed the research approach. X.W. and Y.S. provided guidance and instrumental support. S.Y., W.C. and Z.M. collected and analyzed the XRD and XPS data. Y.Z. and Y.D. conducted the TEM analysis. All authors contributed to the data analysis and manuscript revision.

\section{Competing interests}

The authors declare no competing interests.

\section{Additional information}

Supplementary information is available for this paper at https://doi.org/10.1038/s41598-020-63204-3.

Correspondence and requests for materials should be addressed to L.P. or Y.S.

Reprints and permissions information is available at www.nature.com/reprints.

Publisher's note Springer Nature remains neutral with regard to jurisdictional claims in published maps and institutional affiliations. 
(c) (i) Open Access This article is licensed under a Creative Commons Attribution 4.0 International License, which permits use, sharing, adaptation, distribution and reproduction in any medium or format, as long as you give appropriate credit to the original author(s) and the source, provide a link to the Creative Commons license, and indicate if changes were made. The images or other third party material in this article are included in the article's Creative Commons license, unless indicated otherwise in a credit line to the material. If material is not included in the article's Creative Commons license and your intended use is not permitted by statutory regulation or exceeds the permitted use, you will need to obtain permission directly from the copyright holder. To view a copy of this license, visit http://creativecommons.org/licenses/by/4.0/.

(C) The Author(s) 2020 